\title{
Apuntes para la historia de los carruajes y otros vehículos representativos en el virreinato de Nueva Granada
}

Notes for the History of Carriages and the Other Representative Vehicles in the New Granada Viceroyalty

DOI: https://doi.org/IO.22380/20274688.1520

\begin{tabular}{c}
\hline Recibido: 7 de septiembre del 2020 \\
\hline Aprobado: 8 de marzo del 2021 \\
\hline
\end{tabular}
ÁLVARO RECIO MIR*
Universidad de Sevilla
alvarorecio@us.es

\section{R E S U M E N}

Este artículo recoge las referencias conocidas de los coches que circularon por el virreinato de Nueva Granada y aporta nueva documentación al respecto. Tal contenido, en el marco del mundo hispánico, tendrá como objetivo analizar el desarrollo de su carrocería y mostrar su trascendencia, ya que el carruaje fue uno de los grandes fetiches de distinción social en la Edad Moderna, que afectó tanto a la política como al urbanismo, la arquitectura y la fiesta.

Palabras clave: historia, coche, vehículos representativos, virreinato, Nueva Granada

* Doctor en Historia del Arte y profesor titular de la Universidad de Sevilla. Sus líneas de investigación se centran en el arte español e hispanoamericano de la Edad Moderna. En cuanto a sus publicaciones cabe destacar, junto a los profesores Fátima Halcón y Francisco Herrera, los libros El retablo barroco sevillano (2000) y El retablo sevillano desde sus orígenes hasta nuestros días (2009). Participó en la publicación de Cortijos, haciendas y lagares. Arquitectura de las grandes explotaciones agrarias de Andalucía, en los volúmenes correspondientes a las provincias de Sevilla y Córdoba. Se ha centrado en el estudio del coche de caballos, tanto en España como en América y Filipinas, destacando El arte de la carrocería en Nueva España. El gremio de la ciudad de México, sus ordenanzas y la trascendencia social del coche (2018), galardonado con el premio Nuestra América. https:// orcid.org/0000-000I-7874-5625. 


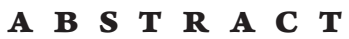

This article collects the known references of carriages that circulated by the viceroyalty of New Granada and provides new documentation on the subject. Such content, within the framework of the Hispanic world, will have as objective to analyze the development of its body shop and to show the social transcendence of matter, since the carriage was one of the great fetishes of social distinction in the Modern Age, that affected so much politics, such as town planning, architecture or partying.

Keywords: History, carriage, representative vehicles, viceroyalty, New Granada

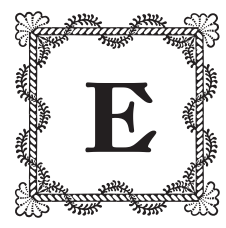

1 carruaje ha sido atendido por la historiografía hispánica solo en fechas muy recientes, a diferencia de lo ocurrido en Alemania, Francia o Inglaterra que cuentan con una notable tradición investigadora al respecto. Todo indica que el papel que España desempeñó en esta historia fue el de darle dimensión planetaria al coche de caballos, surgido en Europa en el tránsito de la Edad Media al Renacimiento, ya que gracias a la corona de Castilla alcanzó los virreinatos americanos desde el siglo XVI, antes que Francia, Inglaterra y otras potencias llevasen los carruajes a sus respectivos imperios coloniales ${ }^{\mathrm{I}}$.

En esta ocasión nos ocuparemos del carruaje en el virreinato de Nueva Granada, para lo que contamos con el interesante precedente del artículo de Harry C. Davidson, "Los coches en Colombia". A pesar de que fue publicado hace más de medio siglo, sigue siendo cimiento fundacional de la historia de la carrocería neogranadina. No obstante, hay que advertir que tal trabajo se basa en fuentes distintas a la documentación de archivo, por lo que habrá que tomar sus referencias con cierta cautela. Por fortuna, en esta ocasión aportaremos nuevos datos, estos sí tomados de documentos de archivo, a lo que sumaremos interpretaciones y comparaciones en el contexto del mundo hispánico.

I Obras de referencia en el ámbito europeo son, entre otras, Wackernagel, Staats-und Galawagen; Piggott; Roche; Furger. Sobre la carrocería hispánica véanse López Álvarez, Poder lujo y conflicto; Galán; Recio, El arte de la carrocería. 


\section{Los antecedentes carreteros y las referencias carroceras previas a la creación del virreinato}

El artículo de Davidson se ocupa mayoritariamente de la carrocería de la Colombia independiente, pese a lo cual da interesantes referencias anteriores. No obstante, al tratar del arte carrocero hay que aludir a su antecedente: la carretería. El carro tuvo su origen en la Antigüedad, pero hasta el final de la Edad Media a esa estructura básica no se añadió un sistema de suspensión, que generó la distinción técnica entre carros y coches (Galán I6-Io9).

Otro artículo de Davidson nos informa de la carretería neogranadina. Refiere, por ejemplo, que en 1564 fue abierto el camino de Santafé a Honda, "entablando en su traxión las primeras requas y carretas". Especifica también que Alonso de Olalla Herrera "descubrió a su costa el camino para el desembarcadero del río Grande de la Magdalena, desde Santa Fe a Onda [...] y le hizo trajinable para recuas, siendo el primero que las tuvo, y carretas" (Davidson, "Los carros" 25I).

También aporta interesantes datos sobre Cartagena, en la que hacia 1590 su cabildo mandó "que los carretones que andan por la ciudad los recojan sus dueños a partes señaladas [...] de noche [...] y días que no trabajan” (Davidson, "Los carros" 25I). Se alude así a los primeros problemas de circulación y a las más antiguas normas al respecto.

De I688 ofrece otra referencia de Cartagena: "sus vecinos usan de tener carretas que las conducen sus esclavos y sirven para llevar de unas partes a otras los bastimentos que se trajinan”. Esta función de transporte de mercancías marcó la diferencia con los coches, los cuales se usaban para personas, de ahí su referido sistema de suspensión. El transporte de materiales en carros también se atestigua en Tunja o Cali (Davidson, "Los carros" 252).

El uso de carros, lógicamente, se mantuvo vigente tras la aparición del coche. De hecho, todo el desarrollo de la carretería fue paralelo, por lo que se refiere a su manufactura, a la evolución del arte carrocero, de lo que se tiene referencias en otros ámbitos americanos (Recio, El arte de la carrocería I68-I84).

En cuanto a los coches propiamente dichos, Davidson apunta que los primeros en Nueva Granada aparecieron en Cartagena de Indias en 1622 y que "se van introduciendo muy deprisa" (Davidson, "Los coches" 446). 
En las entonces capitales virreinales americanas el uso de coches se registra, igual que en la metrópoli, desde mediados del siglo Xvi. Su difusión en ellas, como luego en Cartagena, fue tan rápida que se temió la pérdida de la tradición caballeresca, lo que llevó a Felipe II a dictar una real cédula el 24 de noviembre de 1577 prohibiendo los coches en América. Es muy posible que tan drástica medida frenara la llegada del carruaje al Nuevo Reino de Granada, ya que todo parece indicar que la norma se cumplió (Serrera 292-296; López Álvarez, "Los vehículos"; Recio, El arte de la carrocería 42-50).

La aparición del carruaje en Cartagena en la fecha referida hay que relacionarla con su institucionalización en España bajo Felipe III, que con la pragmática de I6II marcó quién podía - y quién no- usar coche y estableció un sistema de licencias que resultó esencial para formar parte del elitista ámbito cortesano del poder (López Álvarez, Poder, lujo y conflicto I8I-264; López Álvarez, "El nuevo").

El caso de Cartagena pone en evidencia cómo las ciudades se convirtieron en escenario del coche; hay referencia de su rápida progresión en las principales urbes americanas. El carácter pionero del gran puerto caribeńo prueba su primacía entre las ciudades de lo que más tarde sería el virreinato de Nueva Granada².

\section{Falúas y carruajes virreinales y su repercusión en el urbanismo y la fiesta}

La primera referencia a un carruaje en Santafé que recoge Davidson data de I76I, con motivo de la entrada del virrey Pedro Messía de la Cerda, el cual empleó para tan solemne ocasión un "coche que por el señor su antecesor le tenía prevenido", en referencia a José Solís y Folch de Cardona (Davidson, "Los coches" 446).

La primera cuestión que cabe deducir de este apunte es que fija la presencia de coches en la capital desde al menos la década de los años cincuenta del XVIII, cuando gobernó el virrey Solís. No obstante, aunque no contamos con alusiones al respecto, que es posible que aparezcan en futuras investigaciones de archivo, es factible que antes existieran coches en Santafé. Su carácter de capital virreinal entre I7I7 y I724 y definitivamente desde 1739 permite suponer que pudo contar con coches antes de llegar Solís. A ese respecto cabe referir, por

2 Algunas referencias más, aunque no tan específicas como las de Davidson, se recogen en Groot y en Ibáñez. 
ejemplo, que en la remota Manila el origen de la carrocería se fija a inicios del siglo XVIII, vinculado a sus capitanes generales y arzobispos (Recio, "Caballos").

No obstante, quizá la comparación más apropiada sea con Buenos Aires, que se convirtió en capital virreinal poco después que Santafé. Allí la primera referencia a un coche data de I673, y está documentado que en el siglo XVIII tanto los prelados bonaerenses como sus gobernadores tuvieron carruajes, cuyo número aumentó al convertirse en capital virreinal (Torre; Sánchez).

En Santafé, concretamente en el caso del virrey Solís, aunque no contamos con otras referencias que lo vinculen con los carruajes, cabe recordar que destacó como impulsor de carreteras para conectar las principales ciudades neogranadinas (Restrepo). En relación con ello, la Descripción del virreinato de Francisco Silvestre en 1789 destaca de Solís "el carácter blando y cortesano de este Jefe [que] sirvió [par]a docilitar y civilizar mucho la capital” (Silvestre 78). Enlaza ello con la polémica que se originó en España en el siglo XVII al generalizarse los coches, cuando muchas voces alertaron de su carácter muelle, de la pérdida de la tradición caballeresca que ocasionarían y de que, incluso, afeminaban a los hombres (López Álvarez, Poder, lujo y conflicto 4I5-422).

Además, la referencia civilizadora y urbanizadora de Solís hay que conectarla con los carruajes, que tuvieron un carácter básicamente urbano en un principio y se convirtieron en muestra de la importancia de las ciudades en las que abundaban, de lo que es buen ejemplo México, que presumía ufana de ello (Recio, El arte de la carrocería 50-64).

También en relación con lo anterior, cabe recordar que la difusión del carruaje obligó a las ciudades a adaptarse para facilitar su circulación, alineando y ensanchando sus calles. Incluso, surgieron tipologías espaciales para el lucimiento de los coches, como las alamedas. A la cabeza de ellas estuvo la de Hércules de Sevilla, y la primera de América fue la de México, articulándose muy poco después la de los Descalzos de Lima (Recio, "Alamedas").

Ramón Gutiérrez se ha ocupado del caso neogranadino, del que indica que fue precisamente durante el gobierno de Solís cuando se proyectó en Santafé un paseo que vincularía la plaza de San Victorino con la de Armas y que subiría hasta Belén, atravesando el río San Francisco, y bajaría a San Diego, para tomar la antigua alameda y regresar a San Victorino, obra con una concepción lúdica del espacio y que tardaría décadas en perfeccionarse. Señala también que a fines del siglo Xviı el plano de Domingo Esquiaqui recoge todavía la existencia de dos alamedas, la Vieja y la Nueva, obra aparentemente del virrey 
José de Ezpeleta. La voluntad de hacer estas alamedas casi simultáneamente está vinculada a usos peatonales y de cabalgaduras diferenciados, dadas sus distintas extensiones. En relación con ello, y según el cronista Pedro María Ibáñez, dicho virrey se esmeró en "adornar la capital para quitarle su aspecto mezquino", disponiendo una importante arboleda desde la plaza de San Victorino hasta la periferia de San Diego, en lo que habría de ser la llamada alameda Vieja, consolidando quizá un paseo habitual que ya estaba establecido aunque sin precisión. Por su parte, la alameda Nueva tenía un kilómetro desde "el desprendimiento de la calzada de Occidente, debajo de la plaza de San Victorino, hacia Puente Aranda". Así, el paseo tradicional de la capital giró en torno a la plaza de San Victorino, hacia donde los domingos se dirigían algunas de las tres carrozas que había en la ciudad: la del virrey, la del arzobispo y la de los marqueses de San Jorge (R. Gutiérrez 154-156)3.

No obstante, Santafé pese a ser capital del enorme virreinato neogranadino, nunca tuvo una proporcional categoría urbana, ni alcanzó el desarrollo de México o Lima. Como indica Carlos Martínez, en ella no destacó un palacio virreinal, ni grandes edificios públicos, "no lució parques, ni centros de reunión y esparcimiento, ni conformó ese ambiente social fabuloso, alegre y opulento, propio de una corte virreinal". Tampoco por población se pudo comparar con las otras cortes virreinales americanas (Martínez 76-98).

En tal idea insiste Verónica Salazar, que ha interpretado el escaso boato ceremonial de esta corte como reflejo de la débil autoridad de sus virreyes en términos políticos. Su tardía presencia en Nueva Granada y el arraigado poder de audiencias y cabildos, hizo que los virreyes quedasen eclipsados por otras autoridades más asentadas y enraizadas en la sociedad neogranadina (Salazar Io9).

De vuelta a los coches de los virreyes, cabe añadir el que empleó en su toma de posesión en Cartagena, el 3I de octubre de 1772, Manuel de Guirior, al suceder a Pedro Messía de la Cerda. De este acto se dice que

los dos mandatarios subieron al coche virreinal y [...] se dirigieron a la plaza de la Contaduría [...] en la sala de audiencia los esperaban los miembros del cabildo, justicia y regimiento. Los virreyes tomaron asiento bajo dosel. Messía de la Cerda entregó a Guirior el título que contenía su nombramiento. (Aristizábal 28) 
A los anteriores cabe añadir el caso del virrey Pedro Mendinueta y Múzquiz, del que sabemos por una carta de 13 de noviembre de 1796 que había decidido permanecer en Cartagena algún tiempo en vez de dirigirse a Santafé. La razón de ello era que su "media falúa estaba muy dañada", por lo que "ha sido forzoso componerla". A ello añadía: "mañana se comenzará a armar la carroza que también ha tenido mucho que hacer y continuando con el esmero que hasta aquí saldrá el 19 o 20 del presente con los tres champanes de a I8" (Pita 918).

La explícita alusión a que se habría de armar parece indicar que se había traído de España desmontada. De este carácter metropolitano de los coches neogranadinos haremos más referencias en adelante.

En cuanto a las falúas, contamos con referencias anteriores, como la del virrey Juan de Torrezar Díaz Pimienta en I782, cuando remontó el Magdalena en una de estas embarcaciones. Una vez en Santafé "quiso su desgracia o feliz suerte que apeado del coche para entrar a su palacio fuese menester, a breves minutos, suministrarle todos los Santos Sacramentos, agravándose tanto su dolencia por instantes, que falleció a los tres días" (Pérez I24).

Vinculan ambas referencias, coche y falúa, por lo que cabe intuir relaciones entre la carpintería de ribera y el arte carrocero. En cuanto a la embarcación, hay que recordar el uso recreativo de falúas en los reales sitios, en particular las conservadas en el Museo de Falúas Reales de Aranjuez. Estas lujosas embarcaciones las empleaban los monarcas en paseos fluviales de carácter representativo y lúdico. Cabe suponer que, en claro contraste con las canoas y los champanes que surcaban el Magdalena, las falúas neogranadinas serían un claro signo de distinción de los virreyes. Aunque el calificativo de media que se le da en la documentación nos hace suponer que no alcanzarían la riqueza de los modelos reales.

Las falúas neogranadinas contaban en su popa con una estructura cubierta, igual que las españolas, cerrada por cortinas y que cobijaba un sillón para el virrey. Incluso, la comitiva virreinal pasaba la noche en la falúa en caso de no encontrar alojamiento en las poblaciones ribereñas (Aristizábal 40 y 4I).

De vuelta al carruaje del virrey Mendinueta, el documento citado especifica que se trataba de una carroza, que era la denominación de los coches más suntuosos, por ello suponemos que la usaría en su entrada en Santafé, como había hecho su antecesor Díaz Pimienta y era habitual en los demás virreinatos americanos como uno de los máximos atributos de poder (Recio, "La carroza").

Los carruajes formaron parte de la ceremonia de entrada de los virreyes neogranadinos, siguiendo el modelo limeño, como señala Diana Aristizábal. Por ejemplo, en el caso de Flores, su antecesor, Guirior, le envió un coche a la 
cercana localidad de Facatativá. Una vez en la capital, el desfile en coche arrancaba de la calle larga de Las Nieves hasta la plaza de Santo Domingo, donde prestó juramento ante las autoridades, para continuar luego a su residencia (Aristizábal 53).

Por su parte, Roger Pita Pico insiste en que las entradas de los virreyes neogranadinos siguieron el modelo limeño. Así, en 1758, al preparar el recibimiento de Solís se planteó observar la etiqueta de la capital peruana, donde el coche se empleaba en tales fastos desde hacía más de un siglo. No obstante, la adaptación limeña ocasionó problemas, como la carencia en ese momento de coches en Santafé (Pita 92I), lo que apunta a que Solís debió de traer el suyo de España.

Davidson recoge referencias que ponen en evidencia una cierta pomposidad al paso de la carroza virreinal. Alude así a que en los primeros años del siglo XIX "todas las tardes veíamos rodar por aquí [San Diego] algunos carruajes, eran inefables los del virrey, con sus seis caballos, sus batidores y alabarderos de aparato real" (Davidson, "Los coches" 447).

En efecto, el virrey tenía la prerrogativa de emplear tiros de seis caballos, privilegio exclusivo de los miembros de la familia real y de los representantes de los reyes. De igual manera, su carruaje estaba rodeado por la guardia de alabarderos, por su dignidad de capitán general (Recio, "La carroza").

No obstante, el carruaje virreinal no siempre se vio rodeado de tanto aparato ni vinculado a sus entradas. Un caso excepcional es el del virrey Antonio José Amar y Borbón, del que se dice que tuvo una brillantísima entrada. No obstante, fue testigo del comienzo de la independencia y de hecho la revolución que estalló en la capital el 20 de julio de i8ıo ocasionó que fuese depuesto, apresado y expulsado, de manera que la tarde del is de agosto él y su esposa salieron en coche de Santafé (Pumar 213-216).

La imagen del virrey depuesto en su coche no puede ser más expresiva del final de una época. Por desgracia, carecemos de referencias iconográficas de la carrocería neogranadina, pero en el caso hipotético de existir, sin duda esta del virrey Amar y Borbón cerraría el ciclo.

Otra referencia esencial de Davidson, de I8I9, alude a un anónimo oficial británico que aseguraba que en el palacio del virrey Juan de Sámano había “dos carrozas de estado que vimos en una cochera del patio, estaban cargadas de dorados y tenían pinturas de paisajes caprichos" (Davidson, "Los coches" 447).

Destaca el empleo del término "carrozas de estado", que pone de manifiesto el carácter representativo y de atributo y símbolo del poder que el coche 
había alcanzado en Nueva Granada. No menos significativa es la descripción de dichos coches, lo que prueba que seguían aún la modalidad barroca francesa, frente a la inglesa neoclásica, ya implantada en otras capitales americanas y en Europa. Característico de los coches barrocos es que contaron con ciclos pictóricos y abundante decoración de talla dorada, como indica la cita recogida ${ }^{4}$.

Una tercera cuestión interesante es la cochera aludida, ya que, además de al urbanismo, el coche afectó a la arquitectura. Los edificios, empezando por el Alcázar de Madrid, tuvieron que adaptarse a esta realidad. En primer lugar, ampliando sus portadas para que entrasen por ellas los coches. De igual modo, sus apeaderos hubieron de hacerse mayores, para facilitar su maniobrabilidad. Por último, se levantaron cocheras para guardarlos 5 . Junto a la cochera virreinal referida y a la que veremos en relación con los coches de los arzobispos, cabe señalar que el palacio que levantó el virrey-arzobispo Caballero y Góngora en Turbaco también contaba con cochera (Mantilla).

En cualquier caso, todo indica que la llegada de los coches a Santafé está vinculada a la instauración del virreinato, lo que generaría una corte en la cual los símbolos de estatus cobrarían destacado protagonismo. El hecho de que a las anteriores instituciones, arzobispado y audiencia, se sumase la del virrey, permite imaginar significativos cambios en el ceremonial y las habituales rivalidades protocolarias. En tal sentido, resulta ilustrativo que las referencias sobre carruajes en Nueva Granada con las que contamos sean básicamente de virreyes y arzobispos. Así, al afán de lujo y de boato en el mobiliario que se ha vinculado a los virreyes (López Pérez, "Tres momentos" 4I-47), cabría sumar el de los coches.

\section{Los coches y las sillas de manos de los arzobispos de Santafé y sus usos}

Para insistir en la vinculación coche-poder en Nueva Granada, hay que referir el caso de sus prelados. Davidson apunta que el virrey-arzobispo Caballero y Góngora, al renunciar a sus cargos en 1789 , cedió sus coches "a favor de los arzobispos sus sucesores". Se trataba de dos carruajes, "un coche y una berlina", a

4 Sobre la decoración de los coches barrocos remitimos a Wackernagel, Der französische; Recio, "De color"; Recio, "Devociones".

5 Sobre el significativo caso de las cocheras del palacio virreinal de México véase Castro. 
diferencia de cuando llegó en I782, momento en el que en la cochera del palacio arzobispal solo había un "coche viejo". En concreto, de los que legaba especificó que el coche era nuevo, "de cuatro asientos y la berlina de dos, forrados de nuevo y con todos sus cristales de la fábrica de San Ildefonso". A ello añadía que este último fue empleado en I802 para agasajar a Humboldt (Davidson, "Los coches" 477 y 478).

La biografía de Caballero y Góngora de Pérez Ayala, que es la fuente de Davidson, da otros datos. Así, alude a la relación del virrey-arzobispo con las sillas de manos, vinculadas a su patrocinio sobre el Sagrario de la catedral santafereña, ya que en I78I — año que se produjo el motín de los Comunerosencargó una para que fuese tras el sacerdote al llevar el viático a los enfermos y que sirviese de defensa "en cualquier evento". Para tal iniciativa el prelado dispuso 2000 pesos que sufragarían los lacayos que la acarrearan. El capital ofrecido fue tan elevado que se hicieron dos sillas, una para el servicio ordinario y otra para las funciones solemnes. Contaron, además de con los silleros, con un quitasolero, todos uniformados con libreas con botones de hilo de oro y pasamanería. Ambas sillas se usaron hasta I835 (Pérez 58, 59).

Las sillas de manos fueron otros de los vehículos representativos desarrollados junto a los coches, siendo incluso manufacturadas por los mismos carroceros. No tenemos referencias al respecto, pero resulta posible que los arzobispos de Santafé antes de hacer sus entradas en coche las hicieran en sillas, como ocurrió con los prelados de Manila. En cualquier caso, cabe señalar que la silla es apenas una caja sin ruedas para transportar un pasajero, cargada por unos sirvientes llamados silleros que sostenían las dos varas que la alzaban. Se conservan al menos dos del periodo virreinal neogranadino, la primera en la Casa del Escribano de Tunja, de la que se dice que es del siglo xvi; la otra, del xvir, en el Museo Colonial de Bogotá (López Pérez, "Del taller" 90). Corresponden ambas a la tipología habitual de esa época, al estar forradas de cuero fijado con tachuelas doradas. Su presencia en Nueva Granada está atestiguada en otros casos, como el de la esposa del virrey Díaz Pimienta, que la empleó entre el Magdalena y la capital (Aristizábal 53). Por su parte, María del Pilar López Pérez documenta otros ejemplos (López Pérez, "Del taller" 9I).

Con referencia, nuevamente, a los coches de Caballero y Góngora, Pérez Ayala insiste en que en 1789 donó a sus sucesores "toda su librería, coches aperados y menaje de casa que tiene en el palacio arzobispal de Santafé". Los coches se describen como ya vimos, a lo que se añadía que sustituyeron a "los que les robaron sus ingratos diocesanos". Junto a estos carruajes legaba 
también guarniciones para seis mulas, "las mejores que ha tenido su excelencia, que actualmente están sirviendo en el coche” (Pérez 187-193).

El mismo Pérez de Ayala señala que Caballero y Góngora usaba el coche los domingos para ir a la quinta de los arzobispos, cerca de Santafé, donde se conservaba aun en I890, siendo el único de la localidad. Otra referencia de la carroza de Góngora dice que

apenas si cabía en las calles de la ciudad y en las carreteras que a ella dan acceso, hubo necesidad de ampliar estas en algunos puntos para que pudiera cambiar de rumbo, tales son los paréntesis que aun vemos cerca de la quinta de los arzobispos, hoy la Magdalena, y en el camino de Occidente.

También se apunta, en una nueva prueba de la relación urbanismocarrocería, que

el nombre de Las Vueltas del Virrey dado a los paréntesis que se ven todavía en La Magdalena [...] confirman el objeto con que fueron hechos aquellos semicírculos que no era otro que el poder dar la vuelta el pesado carruaje virreinal tirado por varias parejas de mulas. (Pérez I92)

Sin embargo, el "magnífico coche regalado por el virrey arzobispo" tuvo otro uso, ya que "sirvió por muchos años en la procesión de Quasimodo. Se guardaba en la cochera de la casa arzobispal y fue totalmente destruido por la guerrilla de Guasca durante la invasión a Bogotá en I862" (Pérez I92).

En relación con Caballero y Góngora todavía podemos aportar que, a la muerte del arzobispo Fernando Portillo y Torres en I804, un representante del cabildo catedral, Fernando Caycedo, con la intención de defender "tanto los derechos de la yglesia como los de la mitra", solicitó a la audiencia "conservar a la dignidad aquellas alhajas propias de ella y que deben existir en el palacio". En concreto, pidió "que se reserve a la mitra arzobispal el coche, berlina y mulas que dexó el yllustrísimo señor”, que describe como "un coche grande, nuevo, con sus correspondientes guarniciones, seis mulas y una berlina de dos asientos, igualmente buena”. Relata, además, que las usó Martínez Compañón, “dexándolas a su muerte en estado de buen servicio como que sirvieron al yllustrísimo señor difunto". Este último, Portillo y Torres, usó ambos carruajes hasta que "le llegaron el coche y berlina que hizo venir de Santo Domingo". Llegados estos, donó la berlina antigua a Felipe Groot. Por otro lado, se decía del coche antiguo que su "juego de ruedas se prestaba con frecuencia a qualquiera que 
quería amansar caballos cerreros como fue notorio en esta ciudad y también lo es el que por esta causa dicho juego de ruedas se halla hecho pedazos" (AGNC, CO, SC, 2I, 43, D. I8, ff. 452-453 v.).

El citado representante del cabildo insistía en que

de ningún modo se piense en vender la berlina, sino que con sus correspondientes guarniciones y las seis mulas queden en el palacio para reponer la que el ylustrísimo señor difunto enagenó y también que respecto a que el coche grande se halla totalmente deteriorado por un uso muy ageno del fin para que lo dexó el señor donador se mande componer a costa de los caudales del expolio hasta ponerlo en estado de servicio en que se le entregó al señor difunto. (AGNC, $C O$, sC, 2I, 43, D. I8, ff. 453 v.-454)

Se reclamaban de este modo dos vehículos, la berlina de Portillo y Torres y el viejo coche de Caballero y Góngora. Pero, además, se da una información preciosa acerca de los coches neogranadinos al final del virreinato, como su procedencia, en este último caso de Santo Domingo, lo que apunta, al igual que ya hemos señalado para los carruajes de los virreyes, un origen español.

También cabe aludir al uso de estos coches, incluso para domesticar caballos; como medio para pagar servicios, como se especifica en el caso del aludido canónigo Groot ${ }^{6}$; o para el recibimiento de personajes, como el mencionado Humboldt.

En cuanto a las mulas referidas y sus arneses, tendrían que ver con Caballero y Góngora, que en su calidad de virrey ya indicamos que gozaba del privilegio de usar tiros de seis animales. Por otra parte, en el complejo universo artístico que se generó en torno a los coches, destacaron las guarniciones, que alcanzaron una pareja riqueza al arte carrocero. Manufacturadas por guarnicioneros, eran el conjunto de correas de cuero y hebillas, argollas y tachuelas de latón dorado e incluso de metales preciosos que vinculaban los animales al vehículo. De igual forma, los carruajes eran atendidos por numerosos servidores, tanto cocheros como lacayos, que iban lujosamente uniformados, siguiendo en el siglo XVIII la moda francesa.

Otra cuestión interesante es la tipológica, ya que se alude a que Caballero y Góngora tenía una berlina de dos plazas y un coche. El término genérico que 
se utilizó en castellano para los carruajes fue el de coche. Con el desarrollo de la carrocería se fueron distinguiendo diversas tipologías, como la mencionada berlina, caracterizada por estar unidos los ejes de sus ruedas no por una viga, como hasta entonces, si no por dos, lo que le daba mayor estabilidad. Pero lo llamado en la documentación berlina era en realidad un coupé o, castellanizado, cupé, un tipo de berlina cuya caja está cortada, como su nombre francés indica, de ahí su carácter biplaza7.

Un tipo de vehículo del que no hemos encontrado referencias, aunque es posible que existiese en Nueva Granada, fue la litera. Igual que las sillas, carecía de ruedas, ya que su caja, similar a la de los coches, era sostenida por dos largos varales que acarreaban animales. Eran utilizadas para los viajes cuando había que transitar por caminos de herradura, que en el caso de Nueva Granada eran mayoritarios.

De vuelta al uso de los carruajes, destaca su carácter procesional, en la referida celebración de Quasimodo. Davidson dice que, además del ya aludido carruaje arzobispal, para esta procesión eucarística se "mandó construir un elegante coche, que era tirado por dos mulas, con cochero vestido con rica librea", siendo estrenado en la procesión de I79I y del que se especifica que se trajo de la metrópoli (Davidson, "Los coches" 449).

El coche procesional, sobre todo en el Corpus Christi, tuvo su origen en I685, cuando Carlos II cedió el suyo a un sacerdote que llevaba el viático a una enferma. Este hecho fue muy publicitado hasta convertirse en una costumbre que arraigó a ambos lados del Atlántico. Sin duda, se trata de la máxima manifestación del carácter simbólico de los coches al convertirse en custodias rodantes (López Álvarez, Poder, lujo y conflicto II2-I35; Recio, "Los coches de Dios").

\section{La limitada difusión de los carruajes al final del virreinato}

A partir de su uso por virreyes y arzobispos los coches fueron empleados por otros personajes de la sociedad neogranadina, como los ya referidos Groot o Humboldt. La difusión del coche se produjo por emulación, ya que desde sus orígenes fue un verdadero fetiche prestigio, indicativo de un estatus social privilegiado.

7 Sobre la compleja cuestión tipología véase la bibliografía de la nota i. 
Davidson ofrece un nuevo e interesante ejemplo al respecto. Se trata del ya mentado coche del marqués de San Jorge, del que contamos con una descripción. En tal sentido, hay que recordar que el estudio de los coches en este periodo debe partir de un hecho que complica su análisis: la desaparición de todos los ejemplares. De ahí la enorme significación de este caso del que se dice que era "un aparato formidable de cuatro ruedas pintadas de rojo" sobre las que se disponía su caja, a la que se llama "cámara", la cual estaba tapizada de damasco carmesí y contaba con "dos grandes sofás frente el uno al otro". Tal caja estaba suspendida sobre "cuatro fortísimos barrotes de hierro, montados en resortes verticales”. También se mencionaba su pescante sobre las ruedas delanteras, del cual se dice que estaba "fuera de la zona de los resortes, para que el cochero bailara en su asiento por el movimiento de trepidación". El coche también tenía una "galería trasera en la que iba [...] la servidumbre femenina de la casa". A ello sumaba que "la subida al vehículo se hacía por una escalera de hierro doblada al costado de cada portezuela, con las correspondiente vidrieras, persianas y cortinas". Seguía narrando la rica descripción que "ponían en movimiento la enorme máquina cuatro hermosas mulas de perezoso andar, enjaezadas con arneses guarnecidos de plata y un caballo montado por el postillón en silla chocontana para amadrinar las mulas y guiar la caravana" (Davidson, "Los coches" 449 y 450).

Tal referencia pone de manifiesto la enorme complejidad del coche, que iba más allá del propio vehículo. A este había que añadir, para entender esta realidad en movimiento, los animales de tiro, cinco en este caso, solo uno menos que los de los virreyes. También interesante es la alusión a sus arneses, con elementos de plata, así como a los servidores, en concreto, el postillón, que guiaba desde el caballo, y el cochero, desde el pescante. Significativa es la alusión a la silla chocontana, de carácter local y que muestra el desarrollo de la guarnicionería neogranadina. A ello hay que sumar los ocupantes del carruaje, así como su servidumbre ${ }^{8}$.

La referida descripción apunta la importancia que las piezas metálicas cobraron en los carruajes a fines del siglo xvirI. A ello hay que sumar las telas de sus tapicerías, las cortinas y los uniformes de sus servidores; la pintura de las ruedas y la caja o los vidrios de sus ventanas, lo que pone en evidencia la aludida complejidad de estos artefactos.

8 Este conjunto de coche, animales, arnés, servidores y ocupantes se denomina en la actualidad enganche, Véase Rivero. 
No obstante, quizá lo más significativo sea comprobar cómo la nobleza local, al igual que ocurrió con la metropolitana, usó el carruaje. En este caso concreto se trataba del segundo marqués de San Jorge de Bogotá, don José María Lozano de Peralta, sin duda buen ejemplo de tantos criollos enriquecidos, ennoblecidos y que ocuparon altos puestos en la administración colonial, dignos de ser investigados en el futuro en relación con la difusión del carruaje siguiendo los modelos establecidos por virreyes y arzobispos.

Davidson da referencias de otras ciudades, como Popayán. Alude a Jerónimo Torres, el cual en 1807 afirmaba que había intentado comprar un coche mediante un agente en Cádiz, pero que al no conseguirlo decidió hacerlo en Popayán siguiendo el Manual del cochero. En concreto, narra:

hice en la pared baja blanqueada, a falta de papel grande, primero el diseño de los detalles del coche con medidas exactas, como eje, cubos, bocines, llantas, camones, rayos, pinas, resortes, lanzas, collares, etcétera. Dirigime a la casa de moneda en solicitud de obreros. (Davidson, "Los coches" 450)

En cuanto a las materias primas, recibió de Pasto "unas excelentes vaquetas", "de Panamá, los tornillos y fierro dulce y no agrio como el de aquí" y, por último, "de Buga, el granadillo que tanto se aprecia, por ser madera dura, maciza y de precioso color encarnado oscuro". Concluye afirmando que tras "casi tres meses tuve el placer de verlo concluido [...] refrescando [...] con aceite de palma la rueda, la caja y lanzas" (Davidson, "Los coches" 450).

Ello pone de manifiesto que en Nueva Granada no había carroceros, lo que resulta lógico teniendo en cuenta los pocos coches existentes en el virreinato, apuntando la fuente su habitual importación. Pese a ello, la obstinación de Torres le hizo construir el primer carruaje neogranadino, aunque de forma amateur, lo que permite intuir su irrefrenable deseo de contar con uno. Resulta expresivo que al carecer de papel usase una pared para su diseño, a la manera de las monteas arquitectónicas. También de gran significación es que para su ejecución empleara el mencionado Manual del cochero. En tal sentido, cabe señalar que Torres pudo referirse a L'art du menuisier-carrosier, de André Jacob Roubo, publicado en I77I y de tradición barroca francesa, o A teatrise on carriages, de Willian Felton, aparecido en 1794 y que muestra la opción neoclásica inglesa?

9 Sobre los tratados referidos, véanse Roubo y Felton. La influencia de Roubo en España es tratada en López Castán. En relación con la construcción de carruajes remitimos a Turmo. 
Esta descripción muestra la enorme variedad de materiales que configuraban los coches, así como su elevado número de piezas y la complejidad de estas manufacturas, en las cuales la amortiguación y la lubricación tenían un destacadísimo papel.

También este caso pone en evidencia la fascinación social del coche. Torres, según Renán Silva, fue un personaje excepcional que nos dejó un relato de su familia. Su intención era ensalzarla, ya que se trataba de unos emigrantes tardíos, de mediano caudal y sin demasiado reconocimiento. Esto último estamos seguros de que intentó solventarlo Torres con el referido coche, que sin duda sería el único de Popayán, lo que le daría un enorme protagonismo social (Silva).

El coche, no podemos dejar de insistir en ello, fue desde sus orígenes un fabuloso fetiche de prestigio, hasta tal punto que su deseo se convirtió en una patología social. Resultaría en tal sentido de gran interés abordar en futuras investigaciones la vinculación del desarrollo de la carrocería a la evolución de la sociedad santafereña en particular y neogranadina en general ${ }^{10}$.

Otro caso de la difusión de los carruajes neogranadinos que podemos

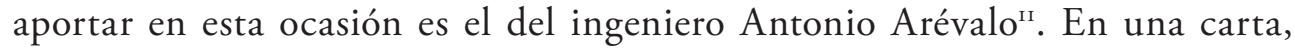
firmada en Cartagena el in de enero de I775, afirmaba que "deseando el excelentísimo señor virrey libertarme de la indispensable pensión de mantener carruaje para los diarios viajes a la obra de Bocagrande", le pidió que "exponga qué gratificación concidero se me podrá señalar para dicho gasto” (AGNC, MM, sc, 37.57.196, f. IO40).

La contestación del virrey al gobernador de Cartagena fue igualmente significativa:

como por real orden de I de septiembre del año próximo pasado tubo a bien su majestad concederme la facultad de que a el brigadier ingeniero en jefe de esa plaza don Antonio de Arévalo y su subalterno les señale las gratificaciones que me parescan por la manutención del carruaje que indispensablemente deben mantener para la diaria asistencia a las obras de Bocagrande, distantes 4.400 varas de esa plaza, cuio clima imposibilita el que puedan andarlas a pie; he resuelto que al expresado brigadier e ingeniero en jefe se le contribuía con la gratificación de cincuenta pesos mensuales y la de treinta presos a su subalterno para el expresado efecto. (AGNC, $M M$, SC, 37.57.196, ff. IO4I-IO42)

Io Punto de partida en tal sentido sería Vargas.

II Sobre este personaje véase, entre otros, Gómez Casado. 
Ello muestra el uso del coche como una suerte de prerrogativa real y la enorme proyección de la monarquía hispánica al respecto, que fue modelo permanente, lo que lo vuelve a vincular al poder.

No obstante, pese a estos casos, el desarrollo de la carrocería en Nueva Granada fue muy limitado, en primer lugar, por su propia orografía. En tal sentido señala Ramón Serrera que la ubicación de la capital en la meseta de Cundinamarca, a ochocientos kilómetros de la costa caribeña, hizo que la supervivencia del territorio se basase en la comunicación entre ambos polos. El medio principal fue el Magdalena, hasta Honda, desde la cual se accedía a Santafé por carretera. En relación con ello señala que a fines del siglo XVIII, a pesar de los esfuerzos borbónicos, el trazado vial del Nuevo Reino de Granada "presentaba un panorama muy arcaico comparado con otras áreas del continente" (Serrera 95-I08).

En la misma línea apunta Secundino Gutiérrez Álvarez, que destaca el papel de Cartagena como llave y pulso del territorio e insiste en la preponderancia del Magdalena como arteria del virreinato hasta Honda, de la que partía un solo camino que se hacía intransitable en época de lluvias (S. Gutiérrez 255-27I).

Santafé no tendría parangón en relación con los coches con México o Lima, ni tan siguiera con Buenos Aires, en la que en 1770 había I6 y en 1800 ascendían a 73 sus propietarios (Sánchez IO2; Torre I64). En cambio, en el caso neogranadino solo tenemos atestiguados los de los virreyes, arzobispos y poco más. Ello, no obstante, haría que tales casos tuvieran un mayor impacto social que los de otras urbes, donde su población llevaba tiempo acostumbrada a estos artefactos.

\section{La proyección de la carrocería virreinal en la Colombia independiente}

El fin de la carrocería virreinal y el inicio de la Colombia independiente se fija en los coches de Simón Bolívar. De él se ha afirmado que tuvo el primer coche "moderno" del país (Davidson, "Los coches" 45I).

Seguramente, el coche más antiguo conservado en Colombia sea precisamente el de Bolívar que se custodia en la quinta de San Pedro Alejandrino, en Santa Marta. Sin duda, la enorme importancia y significación histórica de este vehículo merece un detallado y particular análisis que esperamos acometer en otra ocasión. 
Por otra parte, ya vimos que los coches virreinales se siguieron usando tras la independencia. Contamos con alguna referencia de ese periodo. Así, en I8I4 José Antonio de Ugarte solicitó que de los bienes embargados al difunto Mariano Millán, se le entregase un coche que le pertenecía (AGNC, $S A$, Anexo Grupo I,II.I.34).

Davidson, por su parte, recoge que el norteamericano Guillermo Duane en I822-I823 afirmaba que en Cartagena los únicos coches eran "unas pocas máquinas de construcción pesada, llamadas volantes”. En ello insistía otro viajero de igual procedencia y fecha que apuntaba que dicha ciudad era la única "de Colombia que he visitado en donde se usan carruajes de ruedas" (Davidson, "Los coches" 445 y 446).

De la capital, en I836-I837, se afirmaba que "hay solamente tres carruajes cerrados, uno que pertenece al arzobispo, otro al señor Morales y el tercero al presidente Santander, y solo dos o tres coches de peso liviano y cabriolés". Aunque el mejor era el del presidente, su apariencia era de "un coche de alquiler común, muy desgastado por el uso. Cuando uno de ellos sale, se reúnen multitudes para verlos cuando van rebotando sobre los pavimentos desiguales de Bogotá" (Davidson, "Los coches" 452).

Por su parte, en I 840 el embajador francés indicaba que los coches que había en la ciudad eran

una grande y antigua carroza que hacía parte del mobiliario del arzobispo y que no salía de la cochera sino en circunstancias solemnes, una calesa que le habían regalado a Bolívar y de la cual casi no se servía y un landó que el cónsul general de Inglaterra había traído consigo de Europa. (Davidson, "Los coches" 452 y 453)

A manera de conclusión, cabría señalar que futuras investigaciones permitirán conocer nuevos carruajes, tanto en la capital como en otras ciudades del virreinato. En tal sentido, se habrán de consultar diversas tipologías documentales, como testamentos, cartas, compraventas o normas municipales. Ello mostrará los diferentes ritmos en los que se desarrolló la carrocería en el mundo hispánico, la circulación de coches en tal espacio, su trascendencia social y como se proyectó hasta mediados del siglo XIX, que aquí hemos apuntado en un primer esfuerzo sistematizador para el caso neogranadino ${ }^{12}$.

I2 Ello permitiría conectar con la aparición del tranvía, tratado para nuestro ámbito en Montezuma. 


\title{
$\infty$ \\ B I B L I O G R A F í A
}

\section{I . F U E N T ES PRIMARIAS}

\section{A. Archivos}

\author{
Archivo General de la Nación, Colombia (AGNC) \\ Sección Anexo $(S A)$ \\ Anexo Grupo I,II.I.34. \\ Sección Colonia $(S C)$ \\ Curas y Obispos $(\mathrm{CO})$ \\ SC 21,43 , D. I8. \\ Milicias y Marina $(M M)$ \\ SC, 37.57.196.
}

\section{I F U E N T ESSECUNDARIA S}

Aristizábal García, Diana. Poder y distinción colonial: fiestas del virrey presente y el rey ausente. Nueva Granada, 1770-I800. Bogotá: Universidad del Rosario, 201 I.

Castro, Efraín. Palacio Nacional de México. México: Museo Mexicano, 2003.

Davidson, Harry C. "Los carros de yunta en Colombia". Thesaurus, vol. 22, n. ${ }^{\circ}$, 1967 , pp. $25 \mathrm{I}-256$.

---. "Los coches en Colombia”. Thesaurus, vol. 22, n. ${ }^{\circ}$ 3, 1967, pp. 444-466.

Felton, William. A Treatise on Carriages. Londres: Stationer Halls, 1796.

Furger, Andres. Driving. The Horse, the Man and the Carriage from 1700 up to the Present Day. Hildesheim: Georg Olms Verlag, 2009.

Galán Domingo, Eduardo, coord. Historia del carruaje en España. Madrid: Fomento de Construcciones y Contratas, 2005.

Gómez Casado, Manuel. "La pacificación de La Guajira por el ingeniero Antonio Arévalo. Sobre el proyecto de defensa de Sabana del Valle". Laboratorio de Arte, n. ${ }^{\circ}$ 28, 2016, pp. 373-386. DoI: https://doi.org/I0.12795/la.2006.i.o1.20.

Groot, José Manuel. Historia eclesiástica y civil de Nueva Granada. Bogotá: Foción Mantilla, i 869 . 
Gutiérrez Álvarez, Secundino. Las comunicaciones en América: de la senda primitiva al ferrocarril. Madrid: Mapfre, 1992.

Gutiérrez, Ramón. "La ciudad americana y las alamedas". Las alamedas. Elemento urbano y función social en ciudades españolas y americanas. Barcelona: Ediciones del Sebal, 2019, pp. 83-176.

Ibáñez, Pedro María. Crónicas de Bogotá. Bogotá: Biblioteca de Historia Nacional, 1913-1923.

López Álvarez, Alejandro. "El nuevo cortesano barroco: la institucionalización del coche y las licencias para su uso (el caso de Murcia, I6II-162I)". Las élites en la época moderna: la monarquía española, editado por Enrique Soria Mesa y Juan J. Bravo Caro. Córdoba: Universidad de Córdoba, 2009, t. 4, pp. 269-279.

---. Poder, lujo y conflicto en la corte de los Austrias. Coches, carrozas y sillas de mano, I550-I70o. Madrid: Polifemo, 2007.

---. "Los vehículos representativos en la configuración de la corte virreinal: México y Lima, I590-1700". Materia critica. Formas de ocio y de consumo en la cultura áurea, editado por Enrique García Santo Tomás. Madrid: Universidad de Navarra, 2009, pp. 269-291.

López Castán, Ángel. “El tratado de carpintería y ebanistería de André Jacob Roubo y los extractos publicados por el conde de Campomanes en 1776 ". Anuario del Departamento de Historia y Teoría del Arte, n. ${ }^{\circ}$ 6, 1994, pp. 239-244.

López Pérez, María del Pilar. "Del taller de oficio a las estancias seculares y los espacios sacros: los muebles y sus usos en la vida cotidiana neogranadina”. Catálogo Museo Colonial. Vol. III: mobiliario. Bogotá: Ministerio de Cultura, 2018, pp. 77-98.

---. “Tres momentos de desarrollo del mueble en la Nueva Granada”. Catálogo Museo Colonial. Vol. III: mobiliario. Bogotá: Ministerio de Cultura, 2018, pp. 27-55.

Mantilla, Luis Carlos. "El palacio de los virreyes en Turbaco”. Boletin de Historia y Antigüedades, n. ${ }^{\circ} 835,2006$, pp. 939-948.

Marín, Juana. Gente decente: la élite rectora de la capital, I797-I803. Bogotá: Instituto Colombiano de Antropología e Historia, 2008.

Martínez, Carlos. Santafé. Capital del Nuevo Reino de Granada. Bogotá: Banco Popular, 1988.

Montezuma, Ricardo. La ciudad del tranvia I880-1920. Bogotá: transformaciones urbanas y movilidad. Bogotá: Universidad del Rosario, 2008.

Ojeda Pérez, Robert. Ordenar la ciudad: reforma urbana en Santafé de 1774 a I80I. Bogotá: Archivo General de la Nación, 2007.

Pérez Ayala, José Manuel. Antonio Caballero y Góngora. Virrey y arzobispo de Santa Fe I723I796. Bogotá: Imprenta Municipal, I95I. 
Piggott, Stuart. Wagon, Chariot and Carriage. Symbol and Status in the History of Transport. Londres: Thames and Hudson, 1992.

Pita Rico, Roger. "La llegada de los virreyes al Nuevo Reino de Granada”. Boletín de Historia y Antigüedades, n. ${ }^{\circ}$ 835, 2006 , pp. 913-937.

Pumar Martínez, Carmen. Don Antonio Amar y Borbón, último virrey del Nuevo Reino de Granada. Zaragoza: Centro de Estudios Borjanos, ı991.

Recio Mir, Álvaro. "Alamedas, paseos y coches: función y significación social en España y América (siglos XVI-XIX)". Anuario de Estudios Americanos, vol. 72, n. ${ }^{\circ}$ 2, 2015 , pp. 515-543. DOI: https://doi.org/10.3989/aeamer.2015.2.05.

---. El arte de la carrocería en Nueva España. El gremio de la ciudad de México, sus ordenanzas y la trascendencia social del coche. Madrid: Consejo Superior de Investigaciones Científicas (CSIC), 2018.

--.. “Caballos, sillas de manos y coches en Filipinas: los vehículos representativos en las entradas arzobispales en Manila como símbolos de estatus". Filipinas y el Pacífico. Nuevas miradas, nuevas reflexiones, editado por Salvador Bernabéu, Carmen Mena y Emilio Luque. Sevilla: Universidad de Sevilla, 2016, pp. 517-535.

---. "La carroza del virrey: el coche en Nueva España como atributo del poder". Las artes y la arquitectura del poder, editado por Víctor Mínguez. Castellón de la Plana: Universidad Jaime I, 2013, pp. $2425-2439$.

---. "Los coches de Dios: carrozas y sillas eucarísticas en España y América”. Teatro y fiesta popular y religiosa, editado por Mariela Insúa y Martina Vinatea. Pamplona: Universidad de Navarra, 2013, pp. 269-289.

---. "De color hoja de oliva: la pintura de los coches en la Sevilla del siglo Xviri". Laboratorio de Arte, n. ${ }^{2} 2,2010$, pp. 235-261.

---. "Devociones y aficiones a veces peligrosas: la pintura de los coches novohispanos". Temas americanistas y diversidad cultural. Sevilla: Universidad de Sevilla, 2015, pp. 283-296.

Restrepo Olano, Margarita. Nueva Granada en tiempos del virrey Solís, 1753-176I. Bogotá: Universidad del Rosario, 2009.

Rivero Merry, Luis. Manual de enganches. Sevilla: Caja Rural del Sur, I991.

Roche, Daniel, dir. Voitures, chevaux et attelages du XVIe au XIXe siècle. París: Art Équestre de Versailles, 2000.

Rosa, Moisés de la. Calles de Santa Fe de Bogotá. Bogotá: Academia de la Historia de Bogotá, 1988 .

Roubo, André Jacob. Le menuisier carrossier. París: Inter-livres, 1994. 
Salazar Baena, Verónica. "Fastos monárquicos en el Nuevo Reino de Granada. La imagen del rey u los intereses locales (siglos XVII-XVIII)". Tesis doctoral. Universidad de Barcelona, 2013 .

Sánchez Zinny, Eduardo Florencio. Catálogo del Museo Colonial e Histórico de Luján. Buenos Aires: Arte, 1934.

Serrera, Ramón María. Tráfico terrestre y red vial en las Indias españolas. Madrid: Dirección General de Tráfico, 1993.

Silva, Renán. Los ilustrados de Nueva Granada 1760-1808. Genealogía de una comunidad de interpretación. Medellín: Banco de la República, 2002.

Silvestre, Francisco. Descripción del reyno de Santa Fé de Bogotá. Bogotá: Universidad Nacional de Colombia, 1968.

Torre Revello, José. “Los coches en el Buenos Aires antiguo”. Historia, n. 3, 1956, pp. I6I-I66.

Turmo, Isabel. "Construcción de carruajes”. Reales Sitios, n. ${ }^{13}$, 1967, pp. 33-40.

Vargas Lesmes, Julián. La sociedad de Santafé colonial. Bogotá: Centro de Investigación y Educación Popular, 1990.

Wackernagel, Rudolf H. Der französische Krönungswagen von I696-I825. Ein Beitrag zur Geschichte der repräsentativen Zeremonienswagens. Berlín: Neue Münchner Beiträge zur Kunstgeschichte, 1964.

--- coord. Staats-und Galawagen der Wittelsbacher. Kutschen, Schlitten und Sänften aus dem Marstallmuseum Schlos Nymphemburg. Stuttgart: Arnoldsche, 2002. 